\title{
APPLICATION OF COUPLED EULERIAN-LAGRANGIAN APPROACH IN METAL FORMING SIMULATIONS
}

\begin{abstract}
Numerical simulations of materials forming processes require both powerful computers and advanced software. Large displacements assumed in the analysis usually cause convergence problems. In the Lagrangian approach (typical for solid bodies) a remeshing is frequently necessary. This extends the computations and decreases the convergence. In such cases the application of Euler approach (typical for fluid flows) is an practical alternative. In the Euler approach the finite elements mesh remains fixed, while material flows through it. There is no need for remeshing, therefore. In this paper selected results of coupled Eulerian-Lagrangian analysis are presented. A bent beam as the benchmark test and backward extrusion as an example of metal forming process are considered. Some models parts (tools) are described by updated Lagrangian formulation, other parts (material) are described by Eulerian approach. Obtained results of CEL analyses were compared to ones of the pure Lagrangian approach.
\end{abstract}

Keywords: coupled Eulerian-Lagrangian, large displacements, metal forming

\section{Introduction}

Lagrangian and Eulerian approaches are commonly used in simulations of large displacement problems of solid mechanics. Both formulations have their advantages and limitations. In the Total Lagrangian approach (TL) the initial configuration for the time $t=0$ and the final state for the time $t+\Delta t$ are considered. In the Updated Lagrangian approach (UL) the configurations for the time $t+\Delta t$ are referred to the solution obtained for the time $t$ (Fig. 1).

Unfortunately, as the finite element mesh becomes distorted under the loading, the generation of completely new mesh is required more or less frequently. It causes convergence problems and extends the computation time. In such cases the Eulerian approach becomes more efficient than Lagrangian approach. In the Eulerian formulation the finite element mesh remains fixed, while material flows through it. There is no need for remeshing, therefore. In the ninetieths Lagrangian and Eulerian approaches were combined together in the new approach called coupled Eulerian-Lagrangian (CEL). The CEL method was initially ap- 
plied to fluid-structure interaction problems. In Figure 2 the results of the waterfilled bottle drop-test are presented. The bottle strikes the floor at a skew angle, with one of the bottom corners experiencing the initial impact. A simulation for the bottle accounts both the exterior forces on the bottle from the floor impact, as well as the interior forces of the water pushing against the bottle. Coupled Eulerian-Lagrangian approach may be also applied to metal forming problems. In Figure 3 presented are the results of Lagrangian and CEL rivet forming simulations. Rivets are designed to create permanent attachments between two or more

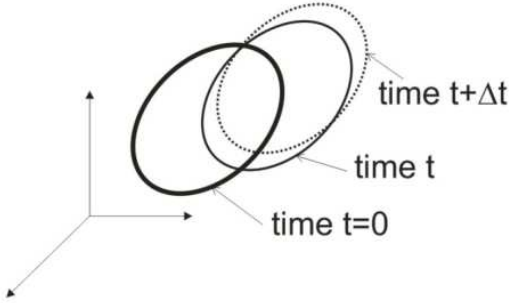

Fig. 1. Reference frames for total Lagrangian and updated Lagrangian

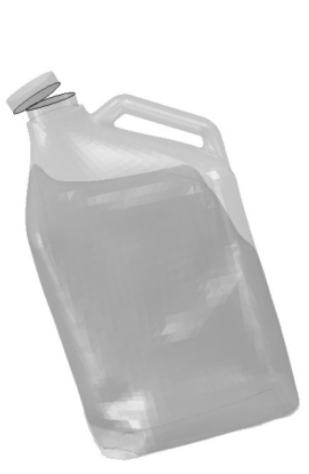

a)
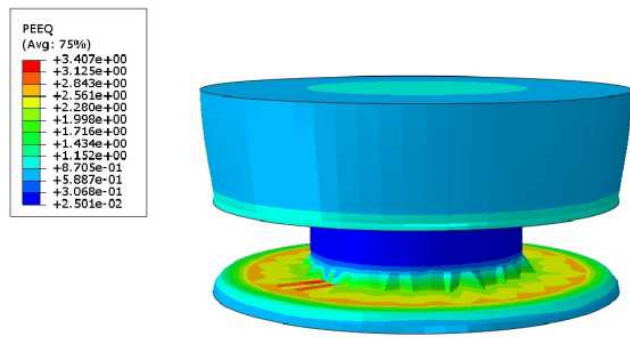

Fig. 2. The water-filled bottle drop-test (CEL model)

b)

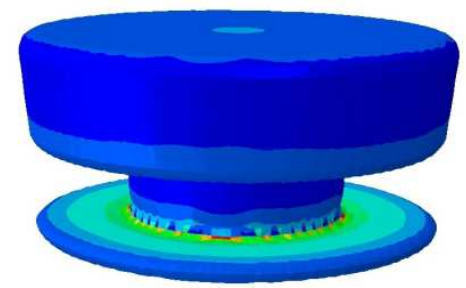

Fig. 3. Equivalent plastic strains in the rivet forming simulation - Lagrangian (a) and CEL (b) analyses 
sheets of material. After both ends of the rivet are compressed the diameter of the rivet body expands, pinching the sheets of material between the two ends of the rivet. The rivet is modeled by Eulerian elements while tools are Lagrangian elements. In both exemplary simulations Lagrangian and Eulerian elements are combined simultaneously in the same model. In the CEL analyses bodies that undergo large deformations are meshed with Eulerian elements, while stiffer bodies in the model are meshed with more efficient Lagrangian elements.

\section{Overview of coupled Lagrangian-Eulerian formulation}

In the Eulerian description equations are written using spatial time derivatives. In the standard Lagrangian description material time derivatives are used. The relation between material and spatial time derivatives is:

$$
\frac{D \Phi}{D t}=\frac{\partial \Phi}{\partial t}+\mathbf{v} \cdot(\nabla \Phi)
$$

where: $\Phi$ - the arbitrary solution variable, $\mathbf{v}$ - the material velocity. $\frac{D \Phi}{D t}$ and $\frac{\partial \Phi}{\partial t}$ are the material and spatial time derivatives, respectively.

The Lagrangian mass, momentum and energy conservation equations transferred into the Eulerian (spatial derivatives) conservation equations [1] are:

$$
\begin{aligned}
& \frac{\partial \rho}{\partial t}+\mathbf{v} \cdot(\nabla \rho)+\rho \nabla \cdot \mathbf{v}=0 \\
& \frac{\partial \mathbf{v}}{\partial t}+\mathbf{v} \cdot(\nabla \cdot \mathbf{v})=\frac{1}{\rho}(\nabla \cdot \boldsymbol{\sigma})+\mathbf{b} \\
& \frac{\partial e}{\partial t}+\mathbf{v} \cdot(\nabla e)=\boldsymbol{\sigma}: \mathbf{D}
\end{aligned}
$$

where: $\rho$ - the density, $\boldsymbol{\sigma}$ - the Cauchy stress, $\mathbf{b}$ - the vector of body forces, $e$ - the strain energy, $\mathbf{D}$ - the velocity strain.

The Eulerian equations (2)-(4) can be written in the conservative forms:

$$
\frac{\partial \rho}{\partial t}+\nabla \cdot(\rho \mathrm{v})=0
$$




$$
\begin{aligned}
& \frac{\partial \rho \mathbf{v}}{\partial t}+\nabla \cdot(\rho \mathbf{v} \otimes \mathbf{v})=\nabla \cdot \boldsymbol{\sigma}+\rho \mathbf{b} \\
& \frac{\partial e}{\partial t}+\nabla \cdot(e \mathbf{v})=\boldsymbol{\sigma}: \mathbf{D}
\end{aligned}
$$

The Eulerian governing equations (5)-(7) have the general form:

$$
\frac{\partial \varphi}{\partial t}+\nabla \cdot \Phi=\mathrm{S}
$$

where: $\Phi-$ the flux function, $S$ - the source term.

Operator splitting divides Eq. (8) into two equations solved sequentially [2]:

$$
\begin{aligned}
& \frac{\partial \varphi}{\partial t}=\mathrm{S} \\
& \frac{\partial \varphi}{\partial t}+\nabla \cdot \Phi=0
\end{aligned}
$$

Eq. (9) contains the source term represents the Lagrangian step. Eq. (10) contains the convective term represents the Eulerian step. Graphical representation of the split operator is shown in Fig. 4.

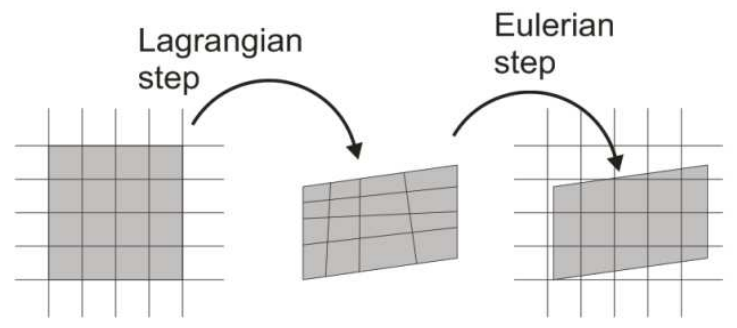

Fig. 4. Split operator for the CEL formulation

To solve Eq. (10) the deformed mesh from Lagrangian step is moved to the Eulerian fixed mesh, and volume of material transported between adjacent elements is calculated. The Lagrangian solution variables (e.g. mass, stress, energy) are adjusted to account for the flow of the material between adjacent elements. For the Lagrangian step the principle of virtual work is applied [3]: 


$$
\int_{V} \rho \mathbf{a} \cdot \delta \mathbf{u} \mathrm{d} v+\int_{V} \boldsymbol{\sigma}: \delta \boldsymbol{\varepsilon} \mathrm{d} V=\int_{S} \mathbf{t} \cdot \delta u \mathrm{~d} S+\int_{V} \rho \mathbf{b} \cdot \delta \mathbf{u} \mathrm{d} V
$$

where: $\delta \mathbf{u}$ - the virtual displacement, $\delta \boldsymbol{\varepsilon}$ - the virtual strain resulting from virtual displacements, $\mathbf{a}$ - the spatial acceleration, and $\mathbf{t}-$ the surface traction. In the Lagarangian step the updated Lagrangian formulation is suitable because the reference configuration (time $t$ ) is the current configuration in the Eulerian approach. Unfortunately, in general the configuration of the body at time $t+\Delta t$ considered in Eq. (11) is unknown (unknown is the volume of integration and density which depends on the body deformations). Moreover, the Cauchy stress at time $t+\Delta t$ cannot be obtained by adding to the Cauchy stress at time $t$ the stress increment because the components of the Cauchy stress tensor change when material is subjected to a rigid body rotation. In practice other strain and stress measures have to be used in the principle of virtual displacements (11) - the Green-Lagrange strain tensor and the second Piola-Kirchoff stress tensor [4]. In order to calculate the material(s) occupation in the Eulerian mesh the volume fraction parameter (VF) is introduced [5]. The initial VF estimation requires the reference volume associated with the fixed regular Eulerian mesh (Fig. 5).

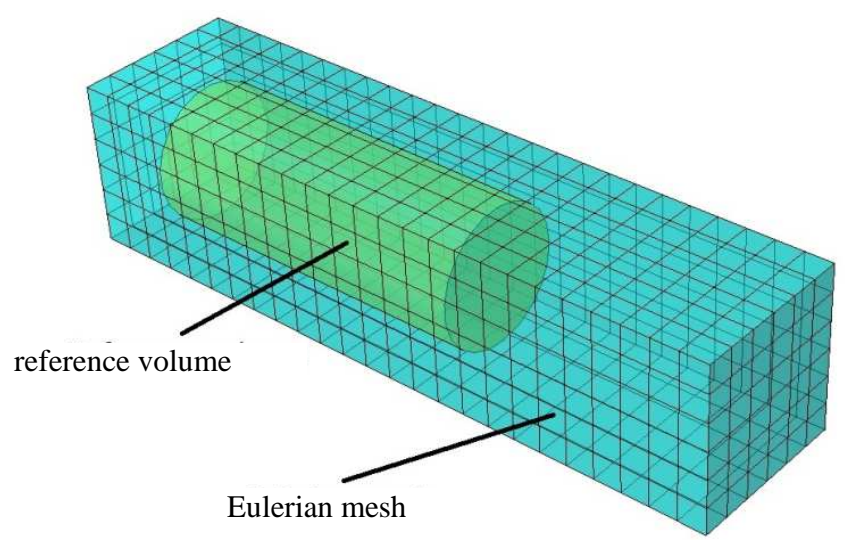

Fig. 5. Reference volume for the volume fraction parameter estimation

\section{Benchmark test - the bent beam}

The bent beam presented in Fig. 6 is considered as the benchmark test. The beam is modeled by Eulerian elements. The initial occupation of beam in 3D space is defined by the reference volume. The Eulerian part of the model sur- 
rounds entirely the beam volume including its later deformations. In Figure 6 one can see two bottom supports and the upper punch being used to apply the load to the beam. Bilinear elastic-plastic material is assumed for the beam. Typically such problems are solved by Lagrangian approach.

The results of the CEL analysis are presented in Fig. 7. The beam deflection and the distribution of stress is similar to ones obtained in pure Lagrangian analysis (not presented here). Unfortunately, in presented CEL analysis all the beam edges are rounded. This is caused by course Eulerian mesh. As a rule, a fine grid resolution comparable with the average radius of geometry curvature is required in Eulerian analyses. External loads can never be applied directly to the Eulerian mesh - contact analysis is the only way to apply a mechanical load

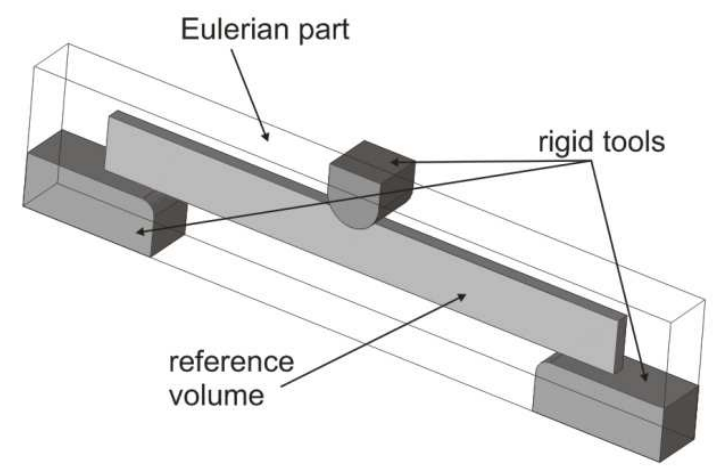

Fig. 6. Bent beam model

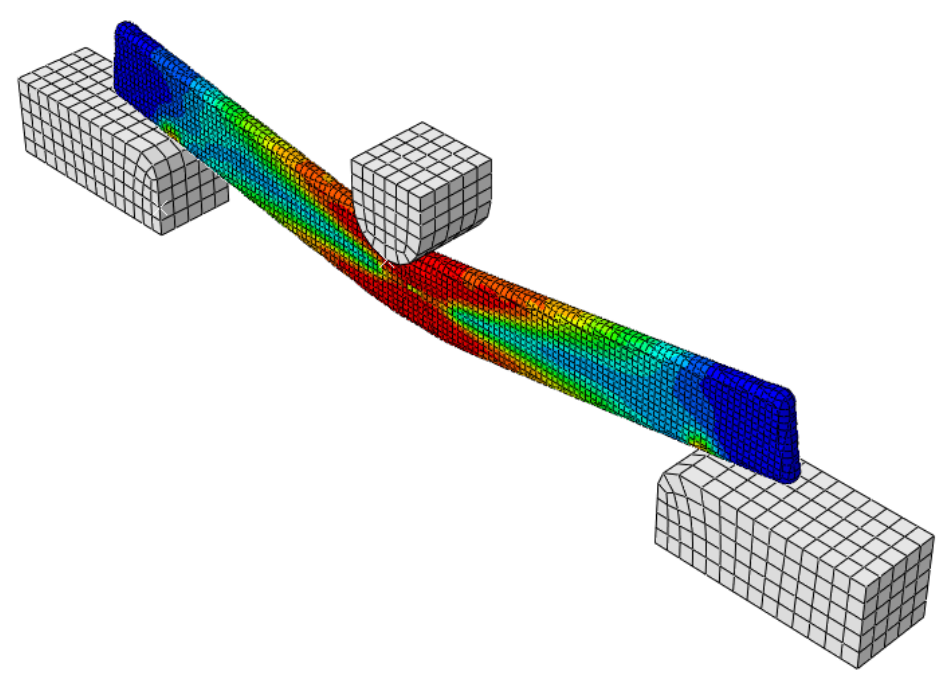

Fig. 7. Equivalent stress in the bent beam CEL analysis 
to Eulerian elements. In this test the load is applied to the beam by rigid tools. In the case of other type of loads (e.g. pressure, concentrated force, moment) aditional flexible parts have to be included in the analysis. Auxiliary Lagrangian flexible parts loaded by mechanical forces affect the Eulerian parts by contact interactions.

\section{Coupled Eulerian-Lagrangian simulation of backward extrusion}

The backward extrusion is a forming process widely used for the manufacturing of solid and hollow parts. The punch strikes the blank extruding it upwards by means of applied high pressure. The analysis of the extrusion forming operations requires evaluation of process parameters such as force and energy consumption as well as the determination of the distribution of the major field variables e.g. plastic strains. Numerical simulations of the backward extrusion process can lead to reduction of forming forces and allow to improve the forming accuracy. Unfortunately, from the mechanical point of view such simulations are very sophisticated. Usually, the finite element mesh becomes very distorted under the load and frequent remeshing is necessary, therefore. Large displacements, contact interactions and remeshing might be the source of convergence problems in Lagrangian analysis. In such cases the Eulerian analysis in which the finite element mesh remains fixed might provide reliable results [6]. The FEM model of the coupled Eulerian-Lagrangian analysis of the backward extrusion process is presented in Fig. 8. The die and recipient are assumed to be rigid bodies. In this simulation the die moves into the cylindrical recipient.

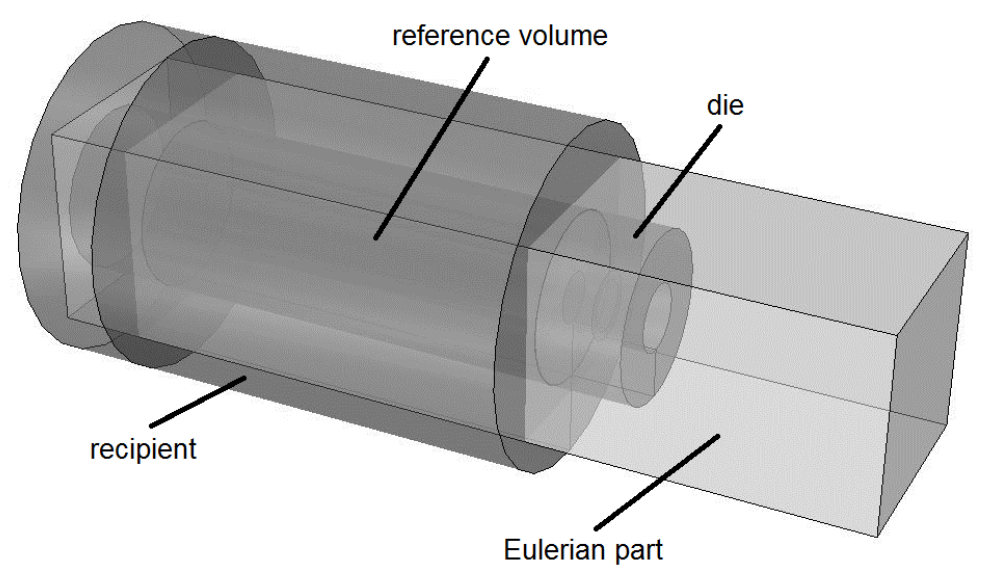

Fig. 8. FEM model of backward extrusion 
The processed material is aluminum alloy at $450^{\circ} \mathrm{C}$. The stress-plastic strain curve is obtained from [7] for Bodner-Partom material model. Assumed B-P material data are: $D_{0}=10^{4} \mathrm{~s}^{-1}, Z_{0}=280 \mathrm{MPa}, Z_{1}=647 \mathrm{MPa}, Z_{2}=35 \mathrm{MPa}$, $Z_{3}=80 \mathrm{MPa}, m_{1}=0,182 \mathrm{MPa}^{-1}, m_{2}=3,7 \mathrm{MPa}^{-1}, r_{1}=r_{2}=4, A_{1}=0,15, A_{2}=0,99$, $n=1,9$. The description of Bodner-Partom material model and its material data is available in [8]. In numerical computations commercial ABAQUS program was used. In ABAQUS program the coupled Eulerian-Lagrangian analysis is restricted to three-dimensional dynamic explicit problems only. Obtained equivalent plastic strain distribution in the extruded bar is shown in Fig. 9. The plot of external work versus the displacement obtained from the simulation is typical for backward extrusion problems (Fig. 10).
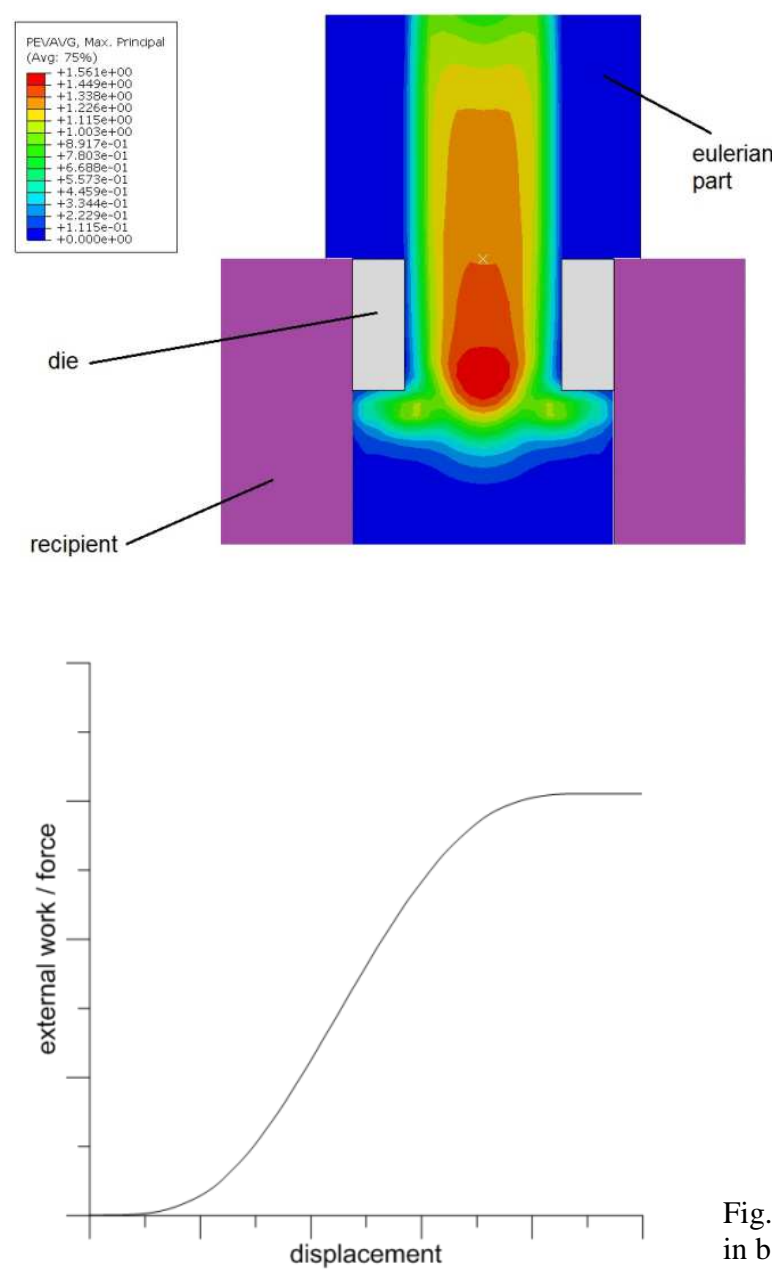

Fig. 9. Equivalent plastic strain distribution in the extruded bar
Fig. 10. External work vs. displacement in backward extrusion 
Considered problem can be solved more efficiently by axisymmetric Lagrangian analysis. Presented results obtained by the CEL analysis are comparable with the results of appropriate Lagrangian analysis which are not presented here. The effectiveness and stability of the CEL analysis can be demonstrated on extrusion problems in which more complicated extruded shapes are considered. In Fig. 11 the non-symmetric skewed double-tee bar used in the aviation industry is presented. Numerical Lagrangian simulation of the extrusion of this profile provides extreme element distortions, and it is both very time consuming and unstable.

Fig. 11. Special double-tee beam used in aviation industry

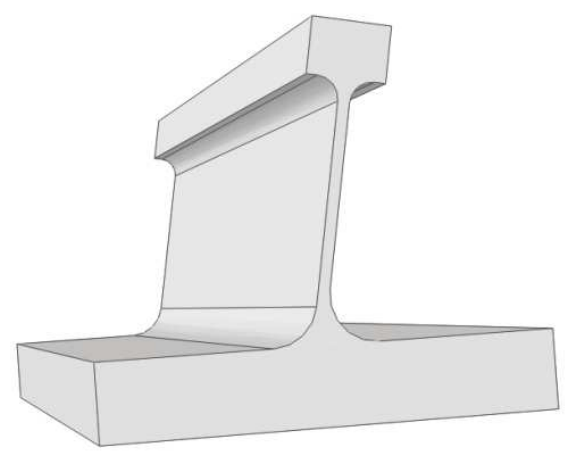

Coupled Eulerian-Lagrangian extrusion analysis runs for this profile without any problems. The only limitation is the size of this task. Thin web of an I-beam provides generation of very small Eulerian elements - material cannot flow through several elements in one time/load increment. Moreover, the dynamic explicit procedure applied here is conditionally stable, and requires very small time increments (of order $10^{-6} \mathrm{~s}$ ) when small finite elements are used. This extends the computation time very much. To solve this problem powerful workstation (12 processors, $24 \mathrm{~Gb}$ of memory) run this problem over two weeks. However, computations based on purely Lagrangian approach even if possible for this sophisticated geometry, would take more time. The geometry of extruded element for early stage of the considered backward extrusion problem is presented in Fig. 12. It should be kept in mind that in ABAQUS post processor in the visualization of the CEL analyses all edges are (unfortunately) rounded.

Presented preliminary simulation is useful in the estimation of the size of the problem, required memory and the computation time in numerical simulations of reversed extrusion of sophisticated-shape elements. Results of such simulations will also help in better design of dies. 


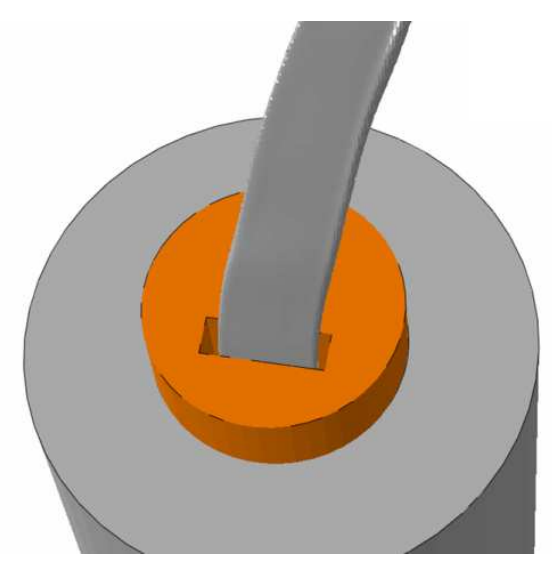

Fig. 12. Backward extrusion of an I-beam profile

\section{Conclusion}

The coupled Eulerian-Lagrangian approach is a very useful tool for solving large displacement problems. Many tasks which are very hard-to-solve by Lagrangian approach can be successfully solved by the CEL analysis. The CEL solution procedure is very stable even for complicated shapes because the Eulerian finite element mesh remains fixed during analysis. The CEL analysis is restricted only to dynamics problems in which inertia forces are considered. In ABAQUS program only explicit integration of the governing equations is allowed. It limits the application of the CEL analysis to short-term problems. In the dynamic explicit approach the stable time increment is usually very small, thus the long-term analysis would require millions of load increments and in consequence would take weeks or even months on powerful workstations. Presented results are very promising. They are stable independently of the shape of extruded elements. The last presented example is very hard to solve by Lagrangian approach. It was efficiently solved by coupled Eulerian-Lagrangian approach. In the future research the results of computer simulations will be compared with the experimental data. In Department of Material Forming and Processing hundreds of backward extrusion tests have been made for various types of materials, different extruded shapes and various temperature. This valuable experimental information will help to select an appropriate material model - in presented simulation simple bilinear elastic-plastic material model was used. One of the candidates is Bodner-Partom material model which allows to take simultaneously into consideration elastic and plastic effects, isotropic and kinematic hardening, visco-plasticity, creep and relaxation for a wide range of temperature. Application of $\mathrm{BP}$ material model in the commercial software (ABAQUS) requires writing user material procedure. 


\section{References}

[1] Benson D.J., Okazawa S.: Contact in a multi-material Eulerian finite element formulation, Comput. Methods Appl. Mech. Engng., 193 (2004), 4277-4298.

[2] Benson D.J.: A mixture theory for contact in multi-material Eulerian formulations, Comput. Methods Appl. Mech. Engng., 140 (1997), 59-86.

[3] Bathe K.J.: Finite element procedures, Upper Saddle River 1996.

[4] Belytschko T., Liu K.W., Moran B.: Non-linear Finite Element Analysis for continua and structures, New York 2000.

[5] Al-Athel K.S., Gadala M.S.: Eulerian volume of solid (VOS) approach in solid mechanics and metal forming, Comput. Methods Appl. Mech. Engng., 200 (2011), 2145-2159.

[6] Gouveia B.P.P.A., Rodrigues J.M.C., Martins P.A.F.: Finite element modeling of cold forward extrusion using updated Lagrangian and combined EulerianLagrangian formulations, J. Mat. Proc. Technol., 80-81 (1998), 647-652.

[7] Bodner S.R.: Unified plasticity for engineering applications, New York - Boston 2002.

[8] Skrzat A.: Fuzzy logic application to strain-stress analysis in selected elasticplastic material models, Arch. Metall. Mater., 56 (2011), 559-568.

\section{ZASTOSOWANIE SPRZĘ̇̇ONEGO PODEJŚCIA EULERA-LAGRANGE'A W SYMULACJACH PROCESÓW PRZERÓBKI PLASTYCZNEJ METALI}

Streszczenie

Numeryczne symulacje procesów przeróbki plastycznej wymagają dużej mocy komputerów oraz zaawansowanego oprogramowania. Uwzględnienie w analizie dużych przemieszczeń jest wielokrotnie źródłem poważnych trudności dotyczących zbieżności obliczeń. W przypadku sformułowania Lagrange'a stosowanego standardowo w analizie odkształcalnych ciał stałych często konieczne jest generowanie zupełnie nowej siatki MES, tzw. remeshingu. Wydłuża to niestety czas analizy i pogarsza jej zbieżność. W takich przypadkach rozsądną alternatywą jest zastosowanie podejścia Eulera (typowego dla analizy przepływu płynów) do obliczeń dużych deformacji ciał stałych. W podejściu Eulera siatka elementów skończonych pozostaje nieruchoma, a przez siatke przepływa materiał. W tym przypadku nie zachodzi konieczność remeshingu i nie pogarsza się uwarunkowanie problemu w czasie trwania obliczeń. W niniejszej pracy przedstawiono przykładowe wyniki obliczeń numerycznych z zastosowaniem sprzężonego podejścia Eulera-Lagrange'a. Jako zadanie testowe analizowano belkę zginaną, jako przykład procesu przeróbki plastycznej rozpatrywano zagadnienie wyciskania przeciwbieżnego. Dla niektórych części modeli (narzędzia) stosowano sformułowanie Lagrange'a, a dla pozostałych części (obrabiany materiał) - sformułowanie Eulera. Uzyskane rezultaty porównywano z wynikami obliczeń, w których zastosowano podejście „,czysto” Lagrange’owskie.

Słowa kluczowe: sprzężona analiza Eulera-Lagrange’a, duże przemieszczenia, kształtowanie plastyczne metali

DOI: $10.7862 / \mathrm{rm} .2012 .9$ 